\title{
Establish an Explored Way of Geography Teaching and Models
}

\author{
Hua Liu \\ Maoming College, Guangdong Province \\ Maoming 525000, China \\ E-mail: LiuHua-5@163.com
}

\begin{abstract}
For the full implementation of the quality of education, education reform is sweeping the earth of the motherland, realizing the reform from materials to the ways of teaching, from the contents to the form, from the form to the essence. However, how can the reform of basic education exist without the reform of normal education? We must face the reality and actively act to carry out a comprehensive reform of teacher education in order to meet the needs of the times. To take the innovation of the teaching methods and establish a new mode of teaching is on the table the biggest task in front of teachers.
\end{abstract}

Keywords: Explored, Geography teaching, Ways and modes

\section{The Research's Background}

\subsection{The International Background}

In the 21 st century human society is pregnant with another great leap - the knowledge economy era. Today science and technology is exploding, international competition in knowledge-based economy is meeting the fierce competition, and the competition of education becomes increasingly intense. Every country is stampeded into reforming the education system so that the quality of basic education can be improved quickly. Of course, China would not want to be left behind.

\subsection{Domestic Background}

In 2000 the Ministry of Education promulgated "the full-time ordinary high school course program (a revised version of the trial)"and "the guide of the research Study implementation in the ordinary high school (Trial)", which aims at to the full implementation of quality education, innovative students' spirit and practical ability to change the way that students are studying and teachers are teaching. "As a result, education reform swept across the country and realized the reform from the teaching materials to the teaching ways, from the content to the form, and from the form to the essence.

\subsection{Unit Background}

We belong to the normal school in higher education institutions, and our students are the teachers of secondary school in the future. However, how can the reform of teacher education exist out of the reform of basic education? How can we achieve the quality of basic education without the improvement of teacher education? Now our teacher education is still mainly the traditional teaching way-based, how can it adapt to the needs of the society? Therefore, we must face the reality and act energetically to carry out a comprehensive reform of teacher education in order to meet the needs of the times. To innovate the teaching ways to establish a new mode of teaching is the greatest task on the table in front of the teachers.

\section{The Research Objectives}

This study focuses on culturing students' scientific inquiry interest, methodology and ability, to emphasize the process of learning and the first-hand experience of exploratory activities. We should pay attention to the following objectives in the implementation process:

\subsection{Culturing Students' Spirit of Scientific Inquiry}

At the scene designed by teachers students can get the first-hand experience of scientific research, to foster interest in and desire for knowledge, and gradually have the courage to question the form, happy to explore, and strive to learn scientific attitude and spirit in the inquiry learning process.

\subsection{Culturing Students' Ability of Science Inquiry}

In the process of inquiry teaching, teachers should update their knowledge structure, improve teaching methods, and encourage students to discover questions and consciously ask questions in the process of study. According to what we have learned, bring forward scientific assumptions, and design science programs to verify that hypothesis. When we are guiding students in designing the program, we have to help them learn how to use various channels to collect, to collate, 
to summarize, to judge and to use information. We should guide students how to analyze the results of the implementary program scientifically, come to conclusions or put forward new problems, and the formation of a written report to enhance their language of expression. Through the whole process of scientific inquiry's practice, we can effectively foster the scientific explore capacity of students.

\subsection{Culturing Students' Ability of Social Adaptation}

Interpersonal communication and cooperation is the basic quality of modern people. The spirit of teamwork should be stressed in the process of inquiry teaching, and in the process of cooperation and fruitful exchanges students will learn to share and cooperation. Through these activities, we can gradually develop and enhance their social adaptability.

\section{The Main Content:}

\subsection{Classroom teaching - "interactive" model [1]}

Classrooms are the main positions of teaching and learning at school. Whether the leading role of teachers and students of the main role can be full played is the key to teaching quality and efficiency. The scientific design of the teaching process is the core of classroom teaching reform.

On the premise of following the cognitive laws, the teaching design should reflect the levels of features: from the shallower to the deeper, step-by-step. So we can found the teaching model such as to stimulate import - to think problems - to systematize knowledge - to expand horizon - the feedback effect. If the teachers guide effectively and students participate actively, so that we can promote the intellectual development of students to achieve the overall optimization of classroom teaching.

\subsubsection{To Stimulate Import}

First of all, we need to create some geographical incident scenes to inspire students' interest and curiosity in the introduction of the new class. Generally, using the video or the multimedia to create geographic incident scenes enables students to think. We can also use the focus and hot spots of social problems to arise students' cognitive attention. We can also use the relative subject knowledge or a variety of charts in teaching materials to let students to assimilate new knowledge based on the original cognitive structure and background knowledge. Second we can quote the suspect to explain the difficult question, to stimulate students' interest in geography, to release their initiative, enthusiasm and subconscious energy. Third, teachers should combine the import to put forward some valuable questions, and then the students can think them. And to encourage students go on divergent thinking and ask more questions.

\subsubsection{To Think Problems}

In order to develop students learning ability and learning initiative, first of all, teachers should careful design the teaching content in the form of questions and wrote on the blackboard when instructing a new lesson, so that students can with a clear objective in mind to read the books on their own initiative. However, teachers must pay attention to the issue of the level, targeted and effective. Secondly, teachers should guide students rightly to learning by themselves, to accept knowledge initiative and easy, to master the main contents and answer questions actively.

The divergent thinking is the core of innovational thinking. In the course of self-study, teacher should induce students to think and find the answers from different angles in time. Their different cognitive and different views burst the sparks of wisdom. At the same time students have doubts about the difficult questions and start to think so that they could learn how to bring the initiative into play. The third, teachers have to control time in the self-study and answering questions. Only time appropriate arrangements can be satisfactorily completed at various aspects of the teaching, to achieve the teaching target and optimize the design class.

\subsubsection{To Systematize Knowledge}

First of all, teachers ought to be targeted for comments about the question that students have answer, and pay attention to intensive comments. The main idea is to help students organize and build a knowledge network schema. Through interactive teaching, students can enrich the knowledge of understanding, and have a clearer idea of learning, which is conducive to widely transfer of learning. Secondly, teachers should combine with comments to build the backbone of knowledge with students, to develop students overall capability. Sort out the level of academic knowledge in context to make it systematic; analysis of the linkages between knowledge, so that it can be structured; sum up the geographical incident's distribution, movement and changes of the law, to make it regular; combine a variety of images, charts, maps with words so that it can be visualized; The contacts and comparisons between evens should have diagrams to make it clear. Which is a formative process of comprehensive analysis, comparative classification, being inducted and deducted, general reasoning with other abilities. Only by classified and systematic the geographical incidents which are seem isolated, establishing the appropriate knowledge system as a whole, which can benefit students grasp the basic knowledge, form a correct integrated cognitive structure to lay the foundation for the further analysis of the 
geographical law .The third, we should pay attention to use of the modern teaching methods and heuristic education.

\subsubsection{To Expand Horizons}

When cultivating the academic ability of students, firstly, we should put emphasis on the interdisciplinary relations and the study of the knowledge cross-points. Secondly, we must guide the students concerned about the social hot spots and focus, imparting consciously such knowledge can reflect that geography is widely available and has social value, introducing the latest progresses and achievements in geography to enhance the spirit of the times of geography, which also can not only extend students' visions but expand their mind. Thirdly, we should consciously link the learned knowledge and practical problems together and use it to explain some natural phenomena and social problems, to enable students to use geographic perspective to observe and analyze the life, production and social realities in the various issues related to geography. Fourthly, to guide students concern about affairs at home and abroad, watch as much as possible programs such as "CCTV News" and "Man and Nature", read newspapers, especially pay particular attention to guide students give sufficient attention to the major events and achievements of science and technology which are involved in the environment, resources, population and development. For example, when speaking of energy, we can allow students to analyze the cause and essence of the U.S. involving in the Middle East the problem from the energy, political, economic, human rights, global strategic and so on; when talking of nuclear fuel, we can let students to discuss the harm caused of he United States and Britain bombing Yugoslavia by depleted uranium bomb; When talking about global climate Warming, to enable students to analyze the reasons, to discuss the harm to identify concrete solutions to foster creativity of our students.

\subsubsection{Feedback Effect}

"Knowledge is the carrier of the ability, the ability is the sublimate of knowledge." Without the accumulation of knowledge, the ability will like the water without its source, the wood without its root. Without the ability, the knowledge has become the dead wood or backwater. This requires that teachers lay a solid foundation in basic knowledge and basic skills instruction, to put forward higher requirements for the knowledge of the study points. Therefore, the teacher has to change the way that teaching-testing-reciting, not only teach the students to learn, but also how to learn by themselves. At this stage, the mainly task is to train our students to summarize, analyze, compare and integrated the geographical events, put their levels of knowledge to a higher stage. In addition, we have to design some related questions to test students to understand the basic content of the materials and we can know whether the goal of teaching can achieve. When we answer to the question of students, we should help students learn to identify errors, to provide feedbacks and reliable basis for the classroom teaching.

In short, through the interactive communication between teachers and students, students received feedback, and constantly reflect on their own and deepen the process of thinking, which will help students develop the ability to innovate and improve classroom teaching. The whole process of teaching is a dynamic process, the student activities-oriented, students are not only the main body of information processing but also a carrier of knowledge, then the final test about the classroom teaching's quality and standards on the basis of students development.

\subsection{Second Class - "Simulated" Model [2]}

The second class is the first class's expanding and addition. Carrying out the second class with a variety of activities can stimulate student's interest in learning geography, reinforcing the control of "double-base" knowledge. The second class is the best way to train the student's the ability to think, to observe, and to simulate, which can raise the effectiveness of the first class teaching.

\subsubsection{By"the Problem Way", Leading Students Study "the Exploring Simulation"}

When we are teaching "Introduction to the Earth", the concept of celestial objects and operation is hard for the students to master. Because it's hard to imagine, and there was no corresponding teaching aids for demonstrations. Teachers have to consciously set up some sense of suspense and vivid image problems, which would make students have the urgent desire of getting the bottom of the matter, thus to stimulate the interest in learning knowledge and the desire to lead. Leading students initiatively to explore the unknown world in the state of mind can bring a great drive to cultivate students to have a comprehensive understanding of laws and essence of the geography. By making special second class activities, let students circumfused the difficult issues in the classroom, make a kind of teaching aids or a wall chart, and show his presentation on a celestial body issues. The activity was very successful. Students's motivatation is high. They divided into study groups, and produced 18 kinds of teaching aids and 6 pieces of wall charts. They elected 4 pieces of wall charts and 2 kinds of teaching aids and gave demonstration on them.

After the activity, a student said: "This is the first time I'm in a teacher's capacity to consider and explain a question. I have to find ways to solve my own teaching aids (wall), to demonstrate on the podium, I'm so worried. But I learn a lot, I think it's successful. I will work hard to be a good teacher." The activity is not only good for students to have interest in geography, deepen their understanding the knowledge of geography, but also making them full of confidence in the 
teaching profession, and enhancing their abilities to think, to do and to simulate teachers.

3.2.2 To Develop the Mind and Intelligence of Students, We Have to Go on Learning the Exploring Simulation.

In teaching teachers should pay attention to cultivating students' habit of association of ideas, fully mobilizing the enthusiasm of the students, and opening up the horizons of science and the realm of thinking. We should pay attention to guiding and developing the students mind, making students to observe, analyze, and judge based on the geographic phenomenon, which can reveal the right way to get the law of conclusions, train student's ability to innovate, and life-long learning ability, and adapt to the society survival and development's abilities.

The first activity is aiming at the main contents of the book, to ask students to make a teaching chart according to the elements of making a map, to select the winner in race, and to show the production and explain all geographic information that the chart can display. The second activity is measuring the activities of the campus and drawing the floor plans. The third is in the lesson of "Theories for Guides", to select some students simulate tour guides and members of the group to simulate tourist to demonstrate a tour activity.

Students expand the horizons of science and the realm of thinking, strengthen the observation, analysis, determination, reasoning ability of students, to achieve the goal that students can have the abilities of innovation and lifelong learning, as well as adapting to the survival and development of the society.

\subsection{Practising Classroom - the "Master-Apprentice" Model[3]}

The practice of teaching is the key to train students' abilities in the applied technology. Aiming at the poor effect of practicing teaching, we should adopt the "master-apprentice" model.

First of all, it should be clearly that the objectives fostering students' capability corresponding to the contents of practice teaching. Second, aiming at different aspects of teaching practice, to employ some engineers and professional teachers with rich practice and teaching experience to establish the relationship between masters and apprentices, carry out the hands-on teaching. Third, after the practice teaching, we should have a examination about demonstration or report. In accordance with the objectives of geography curriculum requirements, the practice lesson of geography should follow the principle that scientific combine thinking, close to students' life, and adapt to the physical and mental development of students. By design, the type can be divided into: the production of hands-on, games and entertainment, observation, visit and survey, audio-visual and reading, lecture and competition, experiment and operation, plan and design, paper-writing, travel and adventure and so on. In accordance with practice contents it can be divided into three categories: Practice, practice teaching, and writing thesis.

\subsubsection{Professional Practice}

First of all, by learning some relevant information, the students can understand the practice content, to master the natural environment and other related knowledge. Mostly students have to understand the geographic location and the regional factors including natural and socio-economic factors which impact on the practice district, and other related knowledge. To be familiar with the basic map of the practice district, to learn how to set the direction on the map, look at the ratio, measure the distance, distinguish the high and the low, know the outline, fill in the mark, draw the section and so on, so as to master how to research all kinds of geographical location on the map, including latitude location, amphibious location and adjacent land. To learn how to determine all kinds of the geographic things' characters, distribution and the reflected the geographical features. To have the ability to read different maps, analyze the relations and affections between the elements of things and the geographical cause. To have the ability of drawing a simple outline, sketch map and distribute chart and so on.

Secondly, to lead the students to go on inspection at the practice district is regarded as the objectives fostering students' capability corresponding to the contents of practice teaching. Aiming at different aspects of teaching practice, to employ some engineers and professional teachers with rich practice and teaching experience to carry out the hands-on teaching. In the course of internship, students can simulate the related departments to discuss regional development and advance some reform programs. They can also be divided into several groups to carry out the research activities, to draw the empoldered drawings or design the empoldered models, and to discuss with others groups.

Third, we should have an evaluation by the ability to operate or practice investigation and design report to evaluate the academic performance at the end of practice.

\subsubsection{Teaching Practice}

The last practice for normal students is teaching practice, which is a large-scale training before they graduate a pre-employment vocational training. The specific processes are to carry out training, to prepare lessons, and to have trial lectures, at last to have classes. There are classes with professional teachers; director training with director; who are carry out the hands-on teaching, to guide the students. 


\subsubsection{Writing Thesis}

This is not only a large-scale training to train the students ability engaged in scientific research, but also lay the foundation for practical work in the future. Specific process is that -teachers and students choose the topic together, professional teachers give some guidance, and then amend it again and again, at last hand on the final papers. Thesis writing is a test and a summary on the university study to students. And it is also a turning point from learning to scientific research. They should be fully prepared for meeting the needs of the society.

To sum up, we can see that the new teaching methods and teaching modes will become more and more with the development of times, changing everyday. But there is something that will never change, and that is, only having the geography teachers with a strong sense of innovation can we have a brand-new of geography teaching, can we bring up the students with innovation ability and the inquiry spirit of geographical science. Let us work hard for it.

\section{References}

Jun Wang. (2003). Vocational Education Training Mode of Inquiry and Practice. Mudanjiang University Transaction. (6)108-110.

Zhen Liu. (2003). Thinking of Optimizing Four the Teaching Models in History. Mudanjiang University Transaction. (7)111-118.

Zhihua Hu. (2004). Chemical Engineering and Technology Training Model. Research on Higher Education. (1)82-85. 